\title{
Medical residents' attitudes and emotions related to Middle East respiratory syndrome in Saudi Arabia
}

\author{
A cross-sectional study
}

Turki Aldrees, MBBS, MBA, Mohammed Al Ghobain, MBBS, Abdullah Alenezi, MBBS, Saleh Alqaryan, MBBS, Dana Aldabeeb, Medical Student, Najed Alotaibi, Medical Student, Kamal Alzahrani, MBBS, Sami Alharethy, MBBS.

\begin{abstract}

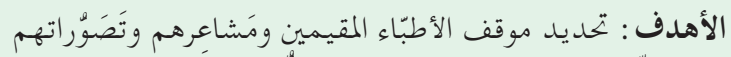

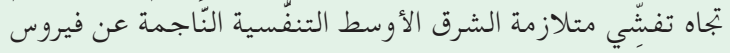
كورونا.

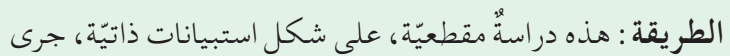

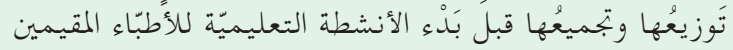

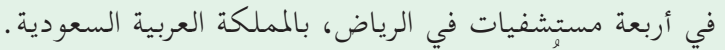

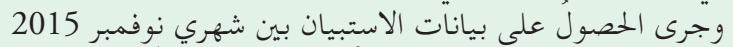

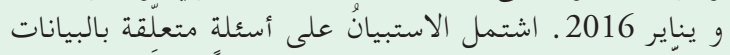

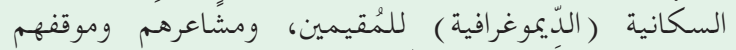

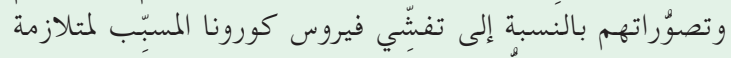

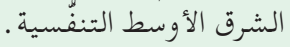

النتائج : من بين 228 مشار كًا خضعوا للدراسة، كان

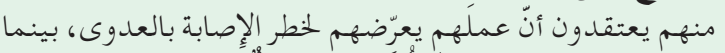

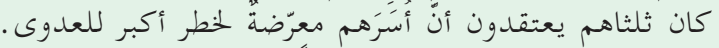

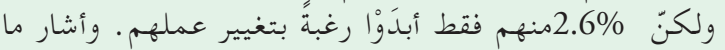

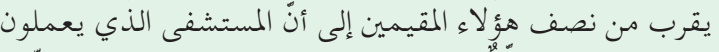

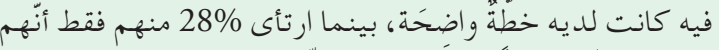

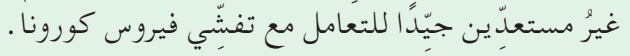

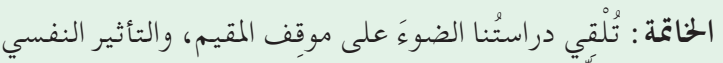

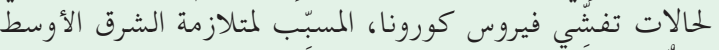

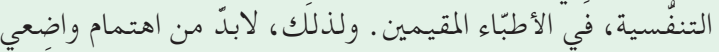

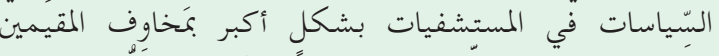

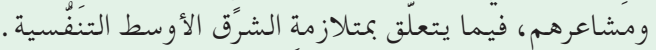

Objectives: To determine medical residents' emotions, attitudes, and knowledge related to Middle East respiratory syndrome (MERS) outbreaks.

Methods: In this is a cross sectional study, selfadministered questionnaires were distributed and collected before resident education activities in 4 tertiary hospitals in Riyadh, Kingdom of Saudi Arabia, between November 2015 and January 2016. The questionnaire included questions related to residents' demographic data and their emotions, attitudes, and knowledge related to an MERS outbreak.

Results: Of the 228 participants analyzed, 85.5\% believed their work put them at risk of infection, and two-thirds believed their family was exposed to a greater risk of infection. However, only $2.6 \%$ would change their job. Nearly half of the residents indicated that their hospital had a clear plan, and only $28 \%$ considered themselves not well prepared for an MERS outbreak.

Conclusions: Our study highlights medical residents' attitude and emotions related to MERS outbreaks. Residents' concerns and emotions in relation to MERS should be considered in greater detail by hospital policymakers.

Saudi Med J 2017; Vol. 38 (9): 942-947

doi: 10.15537/smj.2017.9.20626

From the Department of Otolaryngology-Head and Neck Surgery (Aldrees), College of Medicine, Prince Sattam bin Abdulaziz University, Alkharj, Department of Otolaryngology-Head and Neck Surgery (Alharethy), King Saud University, Department of Internal Medicine, (AlGhobain, Alenezi), National Guard Hospital, Department of Internal Medicine (Alzahrani), King Fahad Medical City, Department of Otolaryngology Head and Neck Surgery (Alqaryan), King Abdulaziz University Hospital, from College of Medicine (Alotaibi, Aldabeeb), King Saud University, Riyadh, Kingdom of Saudi Arabia.

Received 17th April 2017. Accepted 31st May 2017.

Address correspondence and reprint request to: Dr. Turki Aldrees, Department of Otolaryngology-Head and Neck Surgery, College of Medicine, Prince Sattam bin Abdulaziz University, Alkharj, Kingdom of Saudi Arabia. Email: pt.turki@hotmail.com ORCID: http://orcid.org/0000-0001-5284-3956 
$\mathrm{H}_{\mathrm{h}}^{\mathrm{e}}$ ealthcare workers and residents in hospitals are at high risk of Middle East Respiratory Syndrome (MERS) due to their close contact with MERS patients. In addition to the high physical strain of caring for patients potentially infected with MERS, healthcare workers face a tremendous mental burden in doing so, particularly given that the mortality rate of MERS is high, at 36\% (namely, one out of 3 patients die). ${ }^{1}$ The World Health Organization (WHO) claims that MERS, which is caused by a strain of corona virus (called MERS-CoV), is "a threat to the entire world". ${ }^{2}$ The MERS is highly contagious through direct contact with infected patients. Globally, the WHO has reported 1,621 laboratory-confirmed cases of infection with MERS-CoV, and there have been nearly 584 deaths related to MERS-CoV since September 2012. ${ }^{3}$ The first case was reported in 2012 in Jeddah, the Kingdom of KSA, wherein the MERS-CoV was detected in the sputum of a patient with acute pneumonia and renal failure. ${ }^{4}$ Apart from KSA, nearly 22 countries, including the United Arab Emirates, Kuwait, Qatar, Indonesia, the United Kingdom, and the United States, have confirmed MERS cases. ${ }^{3}$ The clinical presentation of MERS ranges from mild flu-like symptoms to severe acute respiratory illness and death; mortality is especially common among patients with comorbidities. Recent epidemiological research has highlighted a number of psychiatric morbidities associated with exposure to devastating epidemics of novel and highly lethal viruses.,6 For medical professionals, the psychological effects of such exposure can jeopardize the medical care they provide. This highlights the need to review the Saudi health care system and policies related to infection control. In the present study, we describe medical residents' emotions, attitude, and perceptions related to an MERS outbreak. Several past studies have examined this for similar, equally threatening, outbreaks such as severe acute respiratory syndrome (SARS) ${ }^{5,6}$ and influenza, ${ }^{7}$ but never for an MERS outbreak. Understanding the fears, anxieties, and reactions of medical residents in close contact with MERS patients may help in devising better personal and family support for hospital employees, which will ultimately aid residents in facing the MERS crisis.

Disclosure. Authors have no conflict of interest, and the work was not supported or funded by any drug company. This study was supported by the College of Medicine Research Center, Deanship of Scientific Research, King Saud University, Riyadh, Kingdom of Saudi Arabia.
Methods. Setting and participants. Four tertiary hospitals in Riyadh, Kingdom of Saudi Arabia (KSA) were included in this study: King Khalid University Hospital, King Fahad Medical City Hospital, King Abdulaziz Medical City Hospital, and King Faisal Specialist Hospital. We included all Saudi Board Internal Medicine residents who rotated into these hospitals between November 2015 and January 2016. Data were collected using self-administered questionnaires, which were distributed and collected before resident education activities. The questionnaire contained a short description of the study aim and objectives. The study was conducted after obtaining ethical approval from the King Saud University Research Center (Research Project Number E-16-1873).

Content of the questionnaire. We adopted and modified an existing questionnaire based on a literature review. ${ }^{8}$ The questionnaire comprised 2 parts. The first part contained questions on participants' background information, including age, marital status, training level (ranging from R1 to R4), and knowledge of MERS (ranging from bad to good). The second part comprised 4 main sections that included an assessment of 1) work-related and 2) non-work related emotions, 3) the residents' attitude toward MERS, and (4 their knowledge of an MERS outbreak. Each question in these sections was measured using a 3-point Likert scale that ranged from "disagree" (1) to "agree" (3). We piloted the questionnaire in a group of 10 residents to assess its clarity.

Statistical analysis. All data were summarized as frequencies (percentages) or medians (interquartile ranges [IQRs]). We examined the relationships between age and the main variables (emotions, attitudes, and knowledge) using Spearman's rank correlations. Spearman's correlations were also used to determine the relationships between work-related concerns and knowledge of an MERS outbreak. All statistical analyses were performed using the Statistical Package for the Social Sciences (IBM Corp., Armonk, NY) version 21.

Results. Response rate and background characteristics. A total of 228 questionnaires were analyzed (response rate: 75\%). Table 1 shows the descriptive statistics of participants' background characteristics. The median (IQR) age was 26 years (25-28 years). Most of participants were male and single (65\% for both), and $94 \%$ of participants rated their level of knowledge about MERS as fair or good

Work- and non-work-related emotions. Table 2 shows the percentage of participants who selected each 
answer option for the work-related and non-workrelated emotions questions. Overall, most of residents agreed that their work put them at risk (85.5\%) and that this risk was a part of their job (60\%). Most of the residents did not agree that they should not look after MERS patients (64\%). Furthermore, while around half of the residents reported being afraid of a MERS infection, $2.6 \%$ reported that they might change their current job due to the risk. At least two-thirds of the

Table 1 - Characteristics of survey respondents of medical residents in 4 tertiary hospital between November 2015 and January 2016.

\begin{tabular}{lr}
\hline Characteristics & $\mathbf{n ~ ( \% )}$ \\
\hline Gender & $148(64.9)$ \\
Male & $80(35.1)$ \\
Female & \\
Marital status & $153(67.0)$ \\
Unmarried & $75(33.0)$ \\
Married & \\
Training level & $92(40.4)$ \\
R1 & $43(18.9)$ \\
R2 & $54(23.7)$ \\
R3 & $39(17.1)$ \\
R4 & $12(5.3)$ \\
Knowledge of MERS & $105(46.0)$ \\
Bad & $11(48.7)$ \\
Fair & $26(25-28)$ \\
Good Age, median (IQR) & \\
\multicolumn{2}{c}{ MERS - Middle Eastern Respiratory Syndrome } \\
\hline
\end{tabular}

residents believed that their job put their family at a greater risk of infection.

Attitude and knowledge of MERS outbreak. Table 3 presents the percentages of participants who selected each answer option for the questions on attitudes toward and knowledge of an MERS outbreak. For the attitude questions, more than half of the respondents disagreed with the idea that people would avoid them and their family due to a higher risk of infection associated with their job. However, nearly $39 \%$ of the residents said agreed that they avoided telling their family about this potentially greater risk. For the knowledge questions, approximately half of the participants reported having attended infection control training and had received adequate personal protective equipment training. Nearly $47 \%$ of residents believed that their hospital had a clear plan for handling a MERS outbreak. However, a minority of residents felt that they were not personally well prepared for a MERS outbreak $(28 \%)$.

Correlation analysis. Correlations between the work-related emotions and knowledge questions are shown in Table 4. Overall, participants who believed their hospital to have a clear plan for handling a MERS outbreak were less likely to feel that they should not look after MERS patients $(\rho=-0.14, \mathrm{P}=0.038)$ or that they might change their job due to the risk of MERS $(\rho=-0.14, \mathrm{P}=0.037)$. Furthermore, they were more likely to agree that the risk of contracting MERS was a part of the job $(\rho=0.16, \mathrm{P}=0.015)$ and to feel

Table 2 - Percentages of responses to the work- and non-work-related emotions questions.

\begin{tabular}{|c|c|c|c|c|}
\hline Questions & $\mathrm{n}$ & $\begin{array}{c}\text { Disagree } \\
(\%)\end{array}$ & $\begin{array}{c}\text { Neutral } \\
(\%)\end{array}$ & $\begin{array}{c}\text { Agree } \\
(\%)\end{array}$ \\
\hline \multicolumn{5}{|l|}{ Work-related emotions } \\
\hline My job puts me at great risk of exposure to MERS & 228 & 5.0 & 9.5 & 85.5 \\
\hline I am afraid of being infected with MERS & 228 & 17.6 & 29.4 & 53.0 \\
\hline I should not look after MERS patients & 228 & 64.0 & 20.6 & 15.4 \\
\hline The risk I am exposed to is unacceptable & 228 & 40.8 & 32.0 & 27.2 \\
\hline I accept that the risk of contracting MERS is a part of my job & 228 & 21.0 & 19.0 & 60.0 \\
\hline I might change my job due to the risk of contracting MERS & 228 & 86.4 & 11.0 & 2.6 \\
\hline I am confident that my hospital would look after me if I were to ever contract MERS & 227 & 23.0 & 20.0 & 57.0 \\
\hline \multicolumn{5}{|l|}{ Non-work-related emotions } \\
\hline \multicolumn{5}{|l|}{ I would be concerned for my: } \\
\hline 1. Wife/husband & 75 & 6.0 & 5.0 & 89.0 \\
\hline 2. Parents & 224 & 7.0 & 8.0 & 85.0 \\
\hline 3. Children & 214 & 9.3 & 25.2 & 65.5 \\
\hline 4. Close friends & 221 & 9.5 & 17.5 & 73.0 \\
\hline 5. Work colleagues & 222 & 7.7 & 17.6 & 74.7 \\
\hline People close to me would be worried about my health & 226 & 6.0 & 19.0 & 75.0 \\
\hline People close to me would be worried that they might get infected through me & 226 & 11.3 & 24.0 & 64.7 \\
\hline
\end{tabular}


Table 3 - Percentages of responses to the attitudes toward and knowledge of an MERS outbreak questions ( $\mathrm{n}=228)$.

\begin{tabular}{|c|c|c|c|}
\hline Question & Disagree & Neutral & Agree \\
\hline I would be afraid of telling my family about the risk I am exposed to & 40 & 21 & 39 \\
\hline People would avoid me due to my job & 59 & 22 & 19 \\
\hline People would avoid my family members due to my job & 85 & 10 & 5 \\
\hline I would avoid telling other people about the nature of my job & 69 & 12.6 & 18.4 \\
\hline $\begin{array}{l}\text { There would be inadequate staff at my workplace to handle the } \\
\text { increased demand }\end{array}$ & 29.8 & 30.7 & 39.5 \\
\hline There would be more conflict among colleagues at work & 35 & 34.7 & 30.3 \\
\hline I would feel more stressed at work & 29.4 & 24.6 & 46 \\
\hline I would see an increase in workload & 36.5 & 7.5 & 56 \\
\hline \multicolumn{4}{|l|}{ Knowledge and preparedness for an MERS outbreak } \\
\hline I have attended infection control training sessions & 36.5 & 7.5 & 56 \\
\hline In our hospital, we have a sufficient number of infection control staff & 26.3 & 30.7 & 43 \\
\hline I have attended infection control-related meetings & 53.9 & 11.4 & 34.7 \\
\hline Our hospital has a clear plan for handling an MERS outbreak & 19 & 34 & 47 \\
\hline I have received adequate personal protective equipment training & 36 & 19 & 45 \\
\hline I am personally prepared for an MERS outbreak & 28 & 33 & 39 \\
\hline
\end{tabular}

MERS - Middle Eastern Respiratory Syndrome.

Table 4 - Spearman's correlations between knowledge of an MERS* outbreak and work-related emotions in the last in the last 6 months.

\begin{tabular}{|c|c|c|c|c|c|}
\hline Standards & $\begin{array}{l}\text { My job puts me at } \\
\text { great risk of exposure } \\
\text { to MERS }\end{array}$ & $\begin{array}{c}\text { I should not be } \\
\text { looking after MERS } \\
\text { patients }\end{array}$ & $\begin{array}{l}\text { I accept that the risk of } \\
\text { contracting MERS is } \\
\text { a part of my job }\end{array}$ & $\begin{array}{l}\text { I might change my job } \\
\text { due to the risk of } \\
\text { contracting MERS }\end{array}$ & $\begin{array}{l}\text { I am confident that my } \\
\text { hospital would look after } \\
\text { me if I were to } \\
\text { ever contract MERS }\end{array}$ \\
\hline $\begin{array}{l}\text { I have attended infection } \\
\text { control training sessions }\end{array}$ & $\begin{array}{l}\rho=0.04 \\
\mathrm{P}=0.552\end{array}$ & $\begin{array}{l}\rho=0.01 \\
\mathrm{P}=0.855\end{array}$ & $\begin{array}{l}\rho-=0.03 \\
\mathrm{P}=0.700\end{array}$ & $\begin{array}{l}\rho=0.13 \\
\mathrm{P}=0.053\end{array}$ & $\begin{array}{l}\rho-=0.03 \\
\mathrm{P}=0.610\end{array}$ \\
\hline $\begin{array}{l}\text { Our hospital has a clear } \\
\text { plan for handling an } \\
\text { MERS outbreak }\end{array}$ & $\begin{array}{l}\rho=-0.04 \\
\mathrm{P}=0.610\end{array}$ & $\begin{array}{l}\rho=-0.14 \\
\mathrm{P}=0.038\end{array}$ & $\begin{array}{l}\rho=0.161 \\
\mathrm{P}=0.015\end{array}$ & $\begin{array}{l}\rho=-0.14 \\
\mathrm{P}=0.037\end{array}$ & $\begin{array}{c}\rho=0.29 \\
\mathrm{P}=0<.001\end{array}$ \\
\hline $\begin{array}{l}\text { I have received adequate } \\
\text { personal protective } \\
\text { equipment training }\end{array}$ & $\begin{array}{l}\rho=-0.03 \\
\mathrm{P}=0.643\end{array}$ & $\begin{array}{l}\rho=0.09 \\
\mathrm{P}=0.190\end{array}$ & $\begin{array}{l}\rho=0.09 \\
\mathrm{P}=0.186\end{array}$ & $\begin{array}{l}\rho=0.04 \\
\mathrm{P}=0.575\end{array}$ & $\begin{array}{l}\rho=0.11 \\
\mathrm{P}=0.099\end{array}$ \\
\hline $\begin{array}{l}\text { I am personally prepared } \\
\text { for an MERS outbreak }\end{array}$ & $\begin{array}{l}\rho=0.08 \\
\mathrm{P}=0.211\end{array}$ & $\begin{array}{l}\rho=-0.20 \\
\mathrm{P}=0.002\end{array}$ & $\begin{array}{l}\rho=0.15 \\
\mathrm{P}=0.026\end{array}$ & $\begin{array}{l}\rho=-0.16 \\
\mathrm{P}=0.019\end{array}$ & $\begin{array}{l}\rho=0.10 \\
\mathrm{P}=0.126\end{array}$ \\
\hline
\end{tabular}

confident that the hospital would look after them if they contracted MERS $(\rho=0.29, \mathrm{p}<0.001)$.

Residents who felt personally ready for a MERS outbreak were more likely to accept the risk as part of their job $(\rho=0.15, \mathrm{p}=0.026)$ and to disagree that they should not look after MERS patients $(\rho=-0.20$, $p=0.002)$ or that they might change their job due to the risk of MERS infection $(\rho=-0.16, \mathrm{p}=0.019)$. We also observed a significant correlation between having received adequate personal protective equipment training and acceptance of the risk as part of their job $(\rho=0.15, \mathrm{p}=0.022)$ As their age increased, respondents were significantly more likely to report being afraid of infection $(\rho=0.15, \mathrm{p}=0.02$, ) and that the risk they were exposed to was unacceptable $(\rho=0.21$, $\mathrm{p}=0.001)$. Respondents who were married were more likely to agree that the risk they were exposed to was unacceptable compared to those who were not currently married $(p=0.005)$. There were no other differences by marital status or gender. As training level increased, participants were more likely to feel that they should not be looking after patients $(p=0.007)$ and that the risk they were exposed to was unacceptable $(p=0.001)$. Finally, participants with higher self-rated knowledge of MERS were more likely to feel that the job put them at risk $(p=0.006)$, but were also more likely to accept the risk as part of their job $(p=0.003)$.

Discussion. We examined the attitudes and emotions related to an MERS outbreak of the medical 
residents serving as frontline physicians in 4 tertiary care hospitals in Riyadh, KSA. Overall, our results indicated that most of medical residents believed their job put them at considerable risk of exposure and were afraid of contracting MERS; however, they also believed that it was part of their professional duty to care for MERS patients and accepted this risk of infection. Participants were also not willing to change their jobs due to the risk of exposure to MERS and they were confident that the hospitals would look after them if they were infected. These results generally accord with 2 recently published studies conducted in KSA among health care workers (HCWs), which sought to examine their attitudes and concerns regarding the emerging outbreak of MERS-CoV. In particular, in both studies, HCWs reported that their job put them at a high risk of contracting the infection. ${ }^{9,10}$ For example, Abolfotouh et $\mathrm{al}^{9}$ reported that around $70 \%$ of surveyed participants felt at risk of contracting a MERS-CoV infection at work, although around $61 \%$ felt obligated to provide medical care for patients infected with MERS-CoV. These findings are also consistent with studies conducted in other countries dealing with different viral outbreaks that had major emotional impacts on healthcare workers. ${ }^{5-7}$ For instance, during the SARS outbreak in 2003, approximately two-thirds of healthcare workers in Toronto experienced concern for their own or their family's health. ${ }^{6}$ In Hong Kong, 68\% of participants reported a high level of stress and 57\% were found to have experienced psychological distress; high stress was much more common among nurses and younger workers. ${ }^{6}$ Unsurprisingly, most medical residents at the 4 centers recognized their professional obligation to look after patients with MERS despite the potential risk to themselves. This contrasts with the findings of a previous study in Australia during the avian influenza outbreak of 2006, wherein a hospital staff absentee rate of $38 \%$ was found. ${ }^{11}$ Similar findings to the Australian study were reported in Hong Kong and Mainland China during the SARS outbreak, wherein a large number of HCWs were absent or refused to look after the infected patients. ${ }^{6}$ By contrast, in Germany, only $28 \%$ of surveyed healthcare workers agreed that it would be professionally acceptable for healthcare workers to abandon their workplace during an influenza pandemic to protect themselves and their families, whereas $52 \%$ disagreed with this statement. ${ }^{12}$ We found that older residents were more likely to report being afraid of infection than were younger residents. This is in contrast to Nickell et $\mathrm{al}^{5}$ study, wherein $73 \%$ of staff who were younger than 30 years of age reported being concerned about infection, compared with only $65.6 \%$ of staff who were older than 50 years Tam et $\mathrm{al}^{6}$ reported a similar finding to Nickell et $\mathrm{al}^{5}$ younger staff members were more prone to job stress during a SARS outbreak than were older staff. However, in both Tam et $\mathrm{al}^{6}$ and Nickle et $\mathrm{al}^{5}$ studies, medical doctors were a minority of participants, making up only $9 \%$ and $3 \%$ of their cohort. In contrast, Wong et $\mathrm{al}^{8}$ report no significant differences in distress among the age groups ${ }^{8}$ In line with our study, Abolfotouh et al ${ }^{9}$ reported that a greater percentage of HCWs who were older than 35 years of age reported a high level of concern about infection than did HCWs who were younger than 35 years $(27 \% \text { versus } 23 \%)^{12}$ Our finding may be attributed to the fact that we included only physicians. In addition, the cultural background of our sample might have influenced our findings: older physicians tend to have families and to be supporting their loved ones. Moreover, the median age of our sample differed from that of previous studies showing that younger staff had more concerns about infection than did older staff. In our study, around half of residents reported receiving adequate training in the use of personal protective equipment. In contrast, a study of HCWs affiliated with the Ministry of Health showed that most of participants lacked confidence in using protective equipment ${ }^{10}$

The difference in findings might be attributed to the fact that our study was conducted at a tertiary hospital, which tend to have more opportunities for continuing medical education and hold more workshops. Moreover, the available level of expertise is often greater than that of primary or secondary hospitals. Another reason might be that we used medical residents as a sample, whereas most of participants in the other studies were nurses. The limitations of the present study include the cross-sectional research design and the possibility of reporting bias. Moreover, because the study was conducted in 4 tertiary hospitals in a single city, the results might not be generalizable to residents in other parts of the country. Although the MERS outbreak started in Jeddah, it has continued since its discovery in 2012 and spread to most of the hospitals in the country, including those involved in this study. Therefore, it is likely that all medical residents in these 4 hospitals had been exposed to or cared for suspected cases of MERS-CoV. Nevertheless, our study provides initial evidence for the attitudes, perceptions, and emotions related to an MERS outbreak among medical residents.

In conclusion, medical residents are the frontline physicians in handling patients with MERS during outbreaks, a fact that causes them and their families 
serious concern and stress. In spite of this, their work performance and patient care does not appear to be affected. All medical staff, including medical residents, should be educated and provided with all the necessary infection control measures as well as effective psychosocial support. Furthermore, medical residents' concerns and stress should be addressed in institutions' planning of MERS outbreak strategies.

\section{References}

1. World Health Organization, Middle East respiratory syndrome coronavirus (MERS-CoV). Geneva (SW): WHO; 2017. Available from: http://www.who.int/mediacentre/factsheets/ mers-cov/en/.

2. Robson S, Malm S. WHO calls Middle Eastern virus, MERS, "threat to the entire world" as death toll rises to 27.29 updated 2013. [Accessed 2016 January 8] Available from: http://www. dailymail.co.uk/news/article-2332677/WHO-calls-MiddleEastern-virus-MERS-threat-entire-world-death-toll-rises-27. html.

3. World Health Organization. Middle East respiratory syndrome coronavirus (MERS-CoV). Geneva (SW): WHO; 2017. Available from: http://www.who.int/emergencies/mers-cov/en/.

4. Zaki AM, van Boheemen S, Bestebroer TM, Osterhaus AD, Fouchier RA. Isolation of a novel coronavirus from a man with pneumonia in Saudi Arabia. N Engl J Med 2012; 367: 1814-1820.

5. Nickell LA, Crighton EJ, Tracy CS, Al-Enazy H, Bolaji Y, Hanjrah S, et al. Psychosocial effects of SARS on hospital staff: survey of a large tertiary care institution. Can Med Assoc J 2004; 170: 793-798.
6. Tam CWC, Pang EPF, Lam LCW, Chiu HFK. Severe acute respiratory syndrome (SARS) in Hong Kong in 2003: stress and psychological impact among frontline healthcare workers. Psychol Med 2004; 34: 1197-1204.

7. Matsuishi K, Kawazoe A, Imai H, Ito A, Mouri K, Kitamura N, et al. Psychological impact of the pandemic (H1N1) 2009 on general hospital workers in Kobe. Psychiat Clin Neuros 2012; 66: 353-360.

8. Wong TY, Koh GC, Cheong SK, Lee HY, Fong YT, Sundram $\mathrm{M}$, et al. Concerns, perceived impact and preparedness in an avian influenza pandemic - a comparative study between healthcare workers in primary and tertiary care. Ann Acad Med Singap 2008; 37: 96-102.

9. Abolfotouh MA, AlQarni AA, Al-Ghamdi SM, Salam M, Al-Assiri $\mathrm{MH}$, Balkhy $\mathrm{HH}$. An assessment of the level of concern among hospital-based health-care workers regarding MERS outbreaks in Saudi Arabia. BMC Infectious Diseases 2017; 17: 4 .

10. Alsahafi AJ, Cheng AC. Knowledge, attitudes and behaviours of healthcare workers in the Kingdom of Saudi Arabia to MERS coronavirus and other emerging infectious diseases. Int J Environ Res Public Health 2016; 13: 1214.

11. Martinese F, Keijzers G, Grant S, Lind J. How would Australian hospital staff react to an avian influenza admission, or an influenza pandemic? Emerg Med Australas 2009; 21: 12-24.

12. Ehrenstein BP, Hanses F, Salzberger B. Influenza pandemic and professional duty: family or patients first? A survey of hospital employees. BMC Public Health 2006; 6: 311.

\section{Supplements}

* Supplements will be considered for work including proceedings of conferences or subject matter covering an important topic

* Material can be in the form of original work or abstracts.

* Material in supplements will be for the purpose of teaching rather than research.

* The Guest Editor will ensure that the financial cost of production of the supplement is covered.

* Supplements will be distributed with the regular issue of the journal but further copies can be ordered upon request.

* Material will be made available on Saudi Medical Journal website 